\title{
How does extracerebral trauma affect the clinical value of S100B measurements?
}

\author{
Søren Ohrt-Nissen, ${ }^{1,2}$ Lennart Friis-Hansen, ${ }^{2}$ Benny Dahl, ${ }^{1}$ Jakob Stensballe, ${ }^{3}$ \\ Bertil Romner, ${ }^{4}$ Lars S Rasmussen ${ }^{3}$
}

${ }^{1}$ Department of Orthopaedic Surgery, Rigshospitalet, University of Copenhagen, Denmark

${ }^{2}$ Department of Clinical Biochemistry, Rigshospitalet, University of Copenhagen, Denmark

${ }^{3}$ Department of Anesthesia, Center of Head and Orthopaedics, Rigshospitalet, University of Copenhagen, Denmark

${ }^{4}$ Department of Neurosurgery, Rigshospitalet, University of Copenhagen, Denmark

\section{Correspondence to}

Søren Ohrt-Nissen,

Departments of Clinical Biochemistry and Orthopedic surgery, Rigshospitalet, Blegdamsvej 9, DK 2100 Copenhagen, Denmark; ohrtnissen@gmail.com

Presented at the 'Fifth International Conference on Biochemical Markers for Brain Damage' in Lund, 13 May 2009.

Accepted 3 September 2010 Published Online First 14 October 2010

\begin{abstract}
Background Protein S100B has proven to be a useful biomarker for cerebral damage. The predictive ability of S100B may, however, be affected by extracerebral injuries. The aim of this study was to investigate serum levels of S100B in patients with either isolated head injury (IHI), multi trauma with head injury (MTHI), or no head injury (NHI). The primary aim was to assess if a significant difference in serum levels of $S 100 B$ could be found between $\mathrm{IH}$ and MTHI patients.

Methods Patients (233) were primarily admitted to the trauma centre. Serum samples were drawn on admission and $6 \mathrm{~h}$ after trauma and then stored at $-80^{\circ} \mathrm{C}$ until analysed. Variables included Abbreviated Injury Scale (AIS) for head trauma, Injury Severity Score (ISS) and 30-day survival.
\end{abstract}

Results Two patients could not be classified. IHI occurred in 28, MTHI in 102 and NHI was found in 101. The median S100B concentrations on arrival were 0.47 , 1.68 and $0.49 \mu \mathrm{g} / \mathrm{l}$, respectively $(\mathrm{p}<0.0001)$. The corresponding values at $6 \mathrm{~h}$ were $0.14,0.31$ and $0.15 \mu \mathrm{g} / \mathrm{l}$, respectively $(\mathrm{p}<0.0001)$. S100B was significantly higher in patients with MTHI than in patients with $\mathrm{HI}$ at both time points ( $p$ values 0.0005 and 0.01 ). There was no significant difference in S100B between patients having $\mathrm{IHI}$ and patients with $\mathrm{NHI}(\mathrm{p}=0.81$ and $p=0.67$ ).

Conclusions High serum levels of S100B were found early after trauma. The highest concentrations of S100B were found in patients with multi trauma. This suggests that $S 100 B$ serum concentrations are significantly affected by extracerebral injuries.

\section{INTRODUCTION}

The S100 proteins are members of the calmodulin/ troponin C superfamily of calcium binding proteins. ${ }^{1} 2$ This protein family includes approximately 25 members, of which one, S100B, is predominantly expressed in nervous tissue, but also, to a lesser extent, in other tissues such as fat, muscle, ${ }^{3}$ melanocytes and long bones. Consequently, S100B can be released in the cases of cerebral and extracerebral injury. ${ }^{4}$ S100B has intracellular and extracellular physiological functions. It is secreted by astrocytes in the brain where it has several intracellular functions, including being part of the cytoskeleton and a modulator of the cell cycle. The extracellular functions are reparative and toxic, ${ }^{5}$ and extracellular S100B has been shown to inhibit myoblast differentiation in rats. ${ }^{6}$

As $\mathrm{S} 100 \mathrm{~B}$ is predominantly expressed by nervous tissue it has been suggested as a marker for traumatic and anoxic brain damage. A reliable biomarker of cerebral injury is of clinical relevance in minor and major head trauma, as it could reduce the number of negative CT scans. Undén et al found that S100B could theoretically reduce CT scans after minor head injury by more than $30 \%$, with maintained patient safety. Furthermore, studies have shown serum levels of S100B to be directly proportional to the severity of injury. ${ }^{4}$ Also, Vos et $a l^{8}$ found that patients with poor outcomes (Glasgow Outcome Scale (GOS) 1-3) had significantly higher serum S100B levels than patients with better outcomes (GOS 4-5) $(p<0.01)$. Therefore, S100B measurements could provide clinicians with valuable information regarding prognosis and relevant therapeutic actions. Previous studies have demonstrated that the serum levels of S100B can predict pathological findings on CT after minor head injury with a high sensitivity $(99 \%)^{9}$ for brain organ damage as well as epidural bleeding. There are indications that the use of S100B could prove to be very cost-effective, safe and perhaps even more sensitive than cerebral CT as it is free from subjective analytical error. ${ }^{9}$ The problem, however, using S100B as a screening tool, is the positive predictive value, which has been shown to be no more than around $30 \%{ }^{9}$

A general topic of debate, regarding the use of biomarkers in trauma patients, has been the role of the half life of the biomarker in question. Therefore, it has been suggested that blood samples should be collected at specific time points after the injury. Regarding S100B, additional knowledge on serum levels in different types of trauma and at different time points would be of interest, as studies have shown that the predictive ability is affected by extra cerebral injuries, such as fractures of the long bones, ${ }^{10}$ thoracic contusions, burns and minor bruises. ${ }^{11}$ These findings have resulted in suggestions of combining measurements of S100B with other biomarkers, including a careful assessment of peripheral non-cerebral injuries. ${ }^{3}$ The purpose of the present study was to investigate serum levels of S100B on admission and $6 \mathrm{~h}$ post injury, in order to assess the possible difference between patients with isolated head injury (IHI), non-head injury (NHI) and multiple trauma with head injury (MTHI). The primary hypothesis was that there is a significant difference in serum levels of S100B on admission between patients with head injury only and patients with multiple injuries, defined as head injury in combination with other injuries.

\section{MATERIALS AND METHODS}

This study was registered at http://www.ClinicalTrials. gov (Identifier: NCT00192907). 


\section{Patients}

Trauma patients primarily admitted to the level one trauma centre at Rigshospitalet, Copenhagen from 2004 to 2005 were included in the study. Patients were enrolled if the trauma team was activated and major trauma was suspected, defined as need for blood sampling. The following exclusion criteria were applied:

- Age $<18$ years

- Diabetes mellitus, immunodeficiency

- Pregnancy

- Major burns (total body surface area of a burn $>10 \%$ )

- Steroid treatment within $24 \mathrm{~h}$

Patient characteristics have previously been described by Stensballe et al. ${ }^{12}$ This study described serum levels of interleukin (IL) 6 and IL 10 in response to trauma and was the basis for the applied exclusion criteria.

\section{Clinical and radiological examination}

Neurological examination and assessment of level of consciousness, according to the Glasgow Coma Score (GCS), were performed on all patients on arrival. In cases where patients were tracheally intubated on arrival, or unable to cooperate to the neurological evaluation, they were registered as having a GCS of 3 .

In all patients the extent of trauma was classified according to the Injury Severity Score (ISS). ISS is based on the Abbreviated Injury Scale (AIS), describing each lesion in six distinct anatomical body regions. The AIS score of the three most severely injured body regions was squared and added together to produce the ISS score. Where the AIS score was unavailable the ISS score was estimated from the patient's medical record.

CT of the brain was performed according to an institutional standardised protocol using $5 \mathrm{~mm}$ slices, accessing signs of traumatic cranial and intracranial injuries such as haemorrhage, oedema and fracture. This information was used to assess the degree of head injury using the AIS protocol.

\section{S100B analysis}

Blood samples were drawn on admission and $6 \mathrm{~h}$ after the trauma. Blood samples were obtained without or with minimal haemostasis ( $<30 \mathrm{~s}$ ), ice-cooled, and, immediately after clotting, centrifuged at $2000 \mathrm{~g}$ for $10 \mathrm{~min}$. Serum samples were frozen within $1 \mathrm{~h}$ of sampling, and stored at $-80^{\circ} \mathrm{C}$ until analysed. The analysis was performed using a fully automated electrochemiluminescence immunoassay (Roche Diagnostics) performed on a Modular $\mathrm{E}$ with an analytical sensitivity of $0.005 \mathrm{mg} / \mathrm{l}$, and a functional sensitivity of $0.02 \mathrm{mg} / \mathrm{l}$. The analytical range of this test is $0.005-39 \mu \mathrm{g} / \mathrm{l}$. The interassay variation was less than $3 \%$.

\section{Statistical analysis}

Mann-Whitney $U$ and Kruskall-Wallis tests were used to compare serum levels of $\mathrm{S} 100 \mathrm{~B}$ on admission and at $6 \mathrm{~h}$ according to type of injury. Variables include age, gender, 30-day survival, AIS for head trauma score (AIS head), GCS and ISS.

- No head injury was defined as an $A I S^{\text {head }}=0$

- Multi trauma with head injury was defined as ISS $>(\text { AIS head })^{2}$

- Isolated head injury was defined as $\left(\text { AIS }{ }^{\text {head }}\right)^{2}=$ ISS.

$\mathrm{p}$ Values $<0.05$ were statistically significant.

\section{RESULTS}

\section{Inclusion}

A total of 901 patients arrived as trauma alerts, but only 402 were at least 18 years of age and needed blood sampling on arrival. Data collection was incomplete in 65,61 were discharged within $6 \mathrm{~h}$ due to minimal injury, 41 fulfilled exclusion criteria and two withdrew consent.

Accordingly, 233 patients were included in the study where 208 blunt traumas and 25 penetrating traumas were recorded. Two-hundred and three blood samples were obtained on arrival and 198 at $6 \mathrm{~h}$. The average time from trauma to the first serum sample was $40 \mathrm{~min}$ (table 1). Blood samples from both time points were available in 168 patients, and S100B levels were significantly lower at $6 \mathrm{~h}$ compared to arrival.

S100B serum levels were significantly different between the three groups on arrival and at $6 \mathrm{~h}(\mathrm{p}<0.0001)$. S100B was significantly higher in patients with MTHI than in patients with IHI at both time points $(p=0.0005$ and $p=0.01$ respectively). There was no significant difference in S100B levels between patients having IHI and NHI ( $p=0.8$ and $p=0.7)$ (table 1).

Likewise, there was no significant difference in AIS head trauma scores between MTHI patients and IHI patients $(\mathrm{p}=0.98)$.

In the IHI and MTHI groups S100B levels were found to be above $0.1 \mu \mathrm{g} / \mathrm{l}$ in $92 \%$ and $98 \%$ of the patients respectively (table 2 ). Seventy-four per cent of the patients in the NHI group had values above $0.1 \mu \mathrm{g} / \mathrm{l}$.

Epidural haemorrhage was seen in four patients. S100B levels were above $0.9 \mu \mathrm{g} / \mathrm{l}$ on arrival in all four patients (table 3 ).

\section{DISCUSSION}

This study shows that extracerebral injuries have a significant impact on the predictive ability of S100B regarding traumatic brain damage. Higher values of S100B were found in the multi traumatised patients than in the IHI group. It was hypothesised that this difference in S100B between the MTHI and the IHI groups could be caused by higher values of the AIS head injury parameter in the MTHI. However, no such difference was

Table 1 Trauma patient characteristics and S-100B serum values

\begin{tabular}{lcccl}
\hline & $\begin{array}{l}\text { Isolated head } \\
\text { injury (N=28) }\end{array}$ & $\begin{array}{l}\text { Multi trauma with head } \\
\text { injury (N=102) }\end{array}$ & $\begin{array}{l}\text { No head injury } \\
\text { (N=101) }\end{array}$ & p Value \\
\hline Age, years & $40.7(27.0-54.5)$ & $42.0(26.3-57.0)$ & $33.9(25.0-46.0)$ & 0.06 \\
Gender, male & $20(71.4 \%)$ & $77(75.5 \%)$ & $76(75.3 \%)$ & 0.90 \\
ISS & $6.5(4.0-9.0)$ & $16.5(8.0-29.0)$ & $9.0(4.0-12.0)$ & $\mathrm{N} / \mathrm{A}$ \\
AIS, Head trauma & $2.7(2.0-3.0)$ & $2.8(2.0-4.0)$ & $\mathrm{N} / \mathrm{A}$ & $\mathrm{N} / \mathrm{A}$ \\
$\mathrm{S} 100 \mathrm{~B}$ on arrival, $\mu \mathrm{g} / \mathrm{l}$ & $0.47(0.24-1.11)$ & $1.68(0.71-6.10)$ & $0.49(0.10-2.16)$ & $<0.0001$ \\
S100B at $6 \mathrm{~h} \mu \mathrm{g} / \mathrm{l}$ & $0.14(0.09-0.29)$ & $0.31(0.16-0.51)$ & $0.15(0.06-0.30)$ & $<0.0001$ \\
Mortality at 30 days & $1(3.6 \%)$ & $18(17.7 \%)$ & $3(3.0 \%)$ & 0.0009 \\
GCS & $14(9.5-15)$ & $13(6-15)$ & $15(15-15)$ & 0.8 \\
\hline
\end{tabular}

Continuous variables reported as median with (IQR), other data reported with proportions.

AIS, Abbreviated Injury Scale; ISS, Injury Severity Score; GCS, Glasgow Coma Score; p, Kruskall Wallis test or $\chi^{2}$ test. 
Table 2 S100B serum concentrations according to intracranial pathology detected by cerebral CT (CCT) in trauma patients

\begin{tabular}{llllr}
\hline & S100B arrival & CCT pathology & No CCT pathology & Total \\
\hline Multi trauma & $>0.1 \mu \mathrm{g} / \mathrm{l}$ & $41(98 \%)$ & $44(94 \%)$ & 85 \\
& $<0.1 \mu \mathrm{g} / \mathrm{l}$ & $1(2 \%)^{*}$ & $3(6 \%)$ & 4 \\
\multirow{4}{*}{ Isolated head injury } & $>0.1 \mu \mathrm{g} / \mathrm{l}$ & $11(92 \%)$ & 47 & 89 \\
& $<0.1 \mu \mathrm{g} / \mathrm{l}$ & $1(8 \%) \dagger$ & $2(13 \%)$ & 25 \\
& & 12 & 16 & 3 \\
No head injury & $>0.1 \mu \mathrm{g} / \mathrm{l}$ & $\mathrm{N} / \mathrm{A}$ & $61(74 \%)$ & 28 \\
& $<0.1 \mu \mathrm{g} / \mathrm{l}$ & $\mathrm{N} / \mathrm{A}$ & $21(26 \%)$ & 21 \\
& & $\mathrm{~N} / \mathrm{A}$ & 82 & 82 \\
\hline
\end{tabular}

*Diffuse axonal injury.

†Mild cerebral oedema.

found. Furthermore, with a cut-off value of $0.1 \mu \mathrm{g} / 1$, it was found that in the group of patients with no history or sign of head injury, 74\% had values above this limit and there was no significant difference in the $\mathrm{S} 100 \mathrm{~B}$ serum levels on arrival or at $6 \mathrm{~h}$ between the IHI and NHI groups.

The present findings are relevant in the process of determining the indications for S100B screening. Other studies have investigated patients with isolated minor head injury and found that a GCS of $14-15$ is an ideal indication for using S100B as a tool for CT triage..$^{9} 13$ It seems that substantial extracerebral damage severely compromises the use of S100B as a screening tool. This is supported by other studies done on patients with no head injury showing elevated serum levels of S100B. ${ }^{89}$

There is some controversy regarding the optimal time for serum sampling to achieve the greatest predictive value of S100B. Some studies have shown that circulating levels of S100B reach peak values 20 min after injury, ${ }^{14}$ and it would seem that the maximal sensitivity could be achieved by early sampling. However, as the present study has shown, the extracerebral contribution is a significant factor and other authors suggest that S100B determination earlier than $6 \mathrm{~h}$ after injury may increase false-positive results. ${ }^{14}$ Furthermore, Raabe et al ${ }^{14}$ showed S100B concentration to be highly time-dependent in the first 3-4 h, whereas at $6 \mathrm{~h}$ levels are stable and the exact sampling time would be less important. It has been demonstrated that extracerebral S100B has a shorter half life than intracerebral S100B, thus it is suspected that sampling again after $6 \mathrm{~h}$ could help differentiate between groups of injury. A significant decrease in serum levels was found after $6 \mathrm{~h}$, but still no difference could be found between patients with IHI and NHI. This indicates that sampling after $6 \mathrm{~h}$ would not improve the predictive value of S100B.

Da Rocha et al ${ }^{15}$ found S100B to be a predictive parameter for fatal outcome in patients with IHI and in multi traumatised patients. They found no differences in serum S100B levels of multi trauma victims with severe traumatic brain injury (TBI) compared to those with isolated severe TBI, indicating that the extracerebral contribution was insignificant at least for the prognostic value of S100B. In contrast, others have demonstrated a significant extracerebral release and concluded that S100B is not

Table 3 Median S100B values in four patients with epidural haemorrhage

\begin{tabular}{lllll}
\hline & $\mathbf{1}$ & $\mathbf{2}$ & $\mathbf{3}$ & $\mathbf{4}$ \\
\hline Arrival S100B $\mu \mathrm{g} / \mathrm{l}$ & 3.57 & 0.966 & 6.31 & 1.01 \\
$6 \mathrm{~h} \mathrm{S100B} \mu \mathrm{g} / \mathrm{l}$ & 0.644 & 0.264 & 0.403 & 0.452 \\
\hline
\end{tabular}

suitable as a predictor for intracerebral injury in patients with substantial extra cerebral injuries. ${ }^{9}$ The present findings support this view in demonstrating no significant difference in the predictive value of S100B between IHI and NHI patients.

A future prospect in the use of $\mathrm{S} 100 \mathrm{~B}$ as a tool for screening could be the development of a protocol for pattern recognition using other biomarkers. One possibility could be the use of glial fibrillar acidic protein (GFAP), which has been shown to be a very specific biomarker for central nervous system pathological abnormality. ${ }^{16-18}$ Perhaps a combined measurement of S100B and a GFAP test could provide a higher specificity for intracranial pathology than serum S100B values alone. More research on the clinical applicability of serum-GFAP is needed. Other biomarkers should also be considered, among those markers for extracerebral injury such as Gc-globulin, which has proven to be highly and almost immediately sensitive to muscle damage. ${ }^{19} 20$ Measuring Gc-globulin levels could serve as an indicator of the amount of extracerebral injury and thereby help the interpretation of S100B serum values.

The ISS scoring system is an index based on the severity of the anatomical injury sustained and this allowed for a reasonable classification. However, the ISS does not take into account the mechanism of trauma (blunt/penetrating), physiological confounders or concurrent medical disease, all of which could have an impact on the S100B serum levels. Increased S100B has been associated with cerebral infectious diseases, heart ischaemia and neurodegenerative disease. ${ }^{21-23}$ Another limitation of this study is that different physicians performed the ISS scoring throughout the study. This kind of scoring is to some extent subjective and some interobserver variability is inevitable. All patients in the present study were primarily admitted from the scene of the accident and the number of subjects with severe head injury was limited. A high proportion of secondarily admitted patients with severe head injury is usually seen in tertiary trauma centres, and, therefore, the value of S100B may be different in that setting. A benefit of S100B may not be detectable due to a type 2 error, if the number of patients with intracranial pathology is low. This could also be relevant to the inability to detect a difference in S100B levels between patients having IHI and NHI. In total, these groups constituted a sample of nearly 130 patients, which allowed detection of a standardised difference of 0.5 with $80 \%$ power at the $5 \%$ significance level. Unfortunately, the variation in S100B was very large, especially at arrival, where the calculated standardised difference was around $4 \mu \mathrm{g} / \mathrm{l}$ in patients with NHI.

In conclusion, elevated serum concentrations of S100B were found early after trauma, especially in patients with multi trauma. This suggests that $\mathrm{S} 100 \mathrm{~B}$ serum concentrations are significantly affected by extracerebral injuries.

Funding Roche Diagnostics donated the S100B reagents.

\section{Competing interests None.}

Ethics approval Routine and study blood sampling was commenced on arrival if major trauma was suspected. Before further sampling, or as soon as possible, written informed consent was obtained from the patients or the next of kin. The local ethics committee (KF 01-160/02, 11-132/02) and the Danish Data Protection Agency approved the study. The study was in accordance with the Helsinki Declaration of 1975 , as revised in 1983.

Contributors JS collected the blood samples and the characteristics of patients. SO-N has participated in the determination of S100B levels and prepared the first draft of the manuscript. L F-H has supervised the blood sample analysis. BD, LSR and BR wrote the protocol and have participated in the statistical analysis as well as the interpretation of the findings. All authors have participated in the revision of the manuscript and are listed as coauthors, but authorship is fulfilled according to the Vancouver rules.

Provenance and peer review Not commissioned; externally peer reviewed. 


\section{REFERENCES}

1. Rintala-Dempsey AC, et al. Insights into $\$ 100$ target specificity examined by a new interaction between S100A11 and annexin A2. Biochemistry 2006:45:14695-705.

2. Santamaria-Kisiel L, Rintala-Dempsey AC, Shaw GS. Calcium-dependent and -independent interactions of the S100 protein family. Biochem J 2006;396:201-14.

3. Netto CB, Conte S, Leite MC, et al. Serum S100B protein is increased in fasting rats. Arch Med Res 2006;37:683-6.

4. Bloomfield SM, et al. Reliability of $\mathrm{S} 100 \mathrm{~B}$ in predicting severity of central nervous system injury. Neurocrit Care 2007;6:121-38.

5. Donato R. Intracellular and extracellular roles of $\$ 100$ proteins. Microsc Res Tech 2003:60:540-51.

6. Donato R, Sorci G, Riuzzi F, et al. S100B's double life: intracellular regulator and extracellular signal. Biochim Biophys Acta 2009;1793:1008-22.

7. Undén J, Romner B. A new objective method for CT triage after minor head injuryserum S100B. Scand J Clin Lab Invest 2009;69:13-7. Review.

8. Vos $\mathbf{P}$, Lamers K, Hendriks J, et al. Glial and neuronal proteins in serum predict outcome after severe traumatic brain injury. Neurology 2004;62:1303-10.

9. Muller K, Townend W, Biasca N, et al. S100B serum level predicts computed tomography findings after minor head injury. J Trauma 2007:62:1452-6.

10. Unden J, Bellner J, Eneroth $M$, et al. Raised serum S100B levels after acute bone fractures without cerebral injury. J Trauma 2005;58:59-61.

11. Anderson RE, Hansson LO, Nilsson 0, et al. High serum S100B levels for trauma patients without head injuries. Neurosurgery 2001;48:1255-8.

12. Steensballe J, Christiansen M, Tønnesen E, et al. The early IL-6 and IL-10 response in trauma is correlated with injury severity and mortality. Acta Anaesthesiol Scand 2009;53:515-21.
13. Biberthaler P, Linsenmeier U, Pfeifer K-J, et al. Serum S-100B concentration provides additional information for the indication of computed tomography in patients after minor head injury. A prospective multicenter study. Shock 2006;25:446-53.

14. Raabe A, Kopetsch 0, Woszczyk A, et al. Serum S100B protein as a molecular marker in severe traumatic brain injury. Restor Neurol Neurosci 2003;21:159-69.

15. da Rocha AB, Schneider RF, de Freitas GR, et al. Role of serum S100B as a predictive marker of fatal outcome following isolated severe head injury or multitrauma in males. Clin Chem Lab Med 2006;44:1234-42.

16. Aurell A, Rosengren LE, Karlsson B, et al. Determination of S-100 and glial fibrillary acidic protein concentrations in cerebrospinal fluid after brain infarction. Stroke 1991;22:1254-8.

17. Blennow M, Rosengren L, Jonsson S, et al. Glial fibrillary acidic protein is increased in the cerebrospinal fluid of preterm infants with abnormal neurological findings. Acta Paediatr 1996;85:485-9.

18. Rosengren LE, Wikkelsø C, Hagberg L. A sensitive ELISA for glial fibrillary acidic protein: application in CSF of adults. J Neurosci Methods 1994;51:197-20.

19. Dahl B, Schiødt FV, Kiaer T, et al. Serum Gc-globulin in the early course of multiple trauma. Crit Care Med 1998;26:285-9.

20. Dahl B, Schiodt FV, Ott P, et al. Plasma concentration of Gc-globulin is associated with organ dysfunction and sepsis after injury. Crit Care Med 2003:31:152-6.

21. Mazzini GS, Schaf DV, Oliveira AR, et al. Ischemic rat heart releases S100B. Life Sci 2005:77:882-9.

22. Undén J, Christenson B, Bellner J, et al. Serum S100B levels in patients with cerebral and extracerebral infectious disease. Scand J Infect Dis 2004;36:10-13.

23. Rothermundt M, Peters $M$, Jochen HM, et al. S100B in Brain Damage and Neurodegeneration. Microsc Res Tech 2003;60:614-32. Review.

\section{Have confidence in your decision making.}
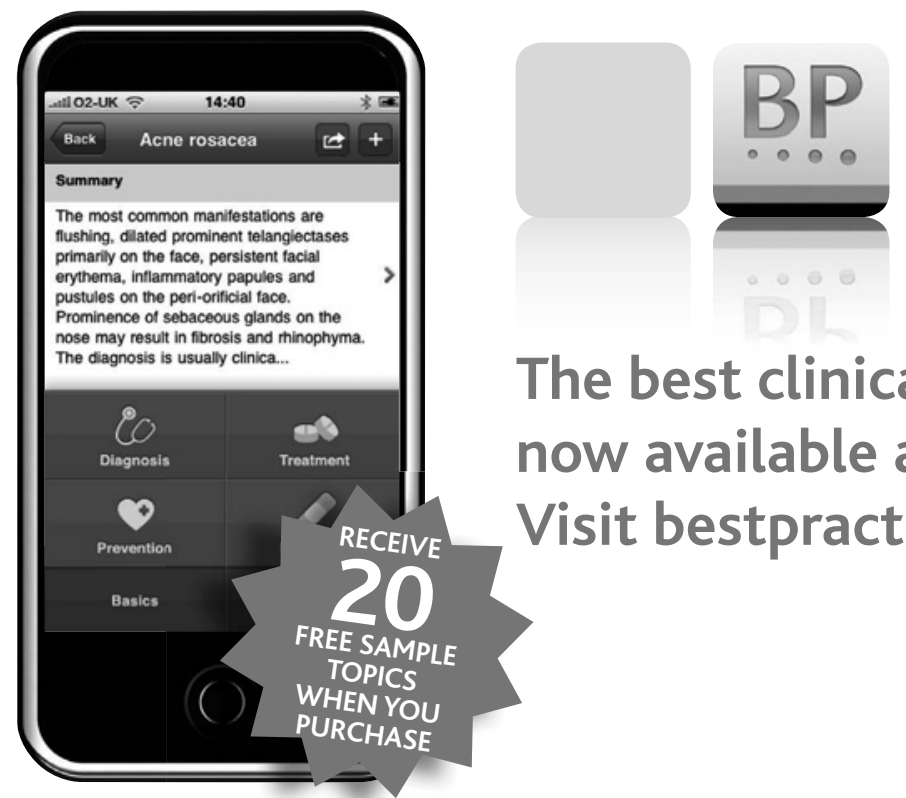

The best clinical decision support tool is now available as an app for your iPhone. Visit bestpractice.bmj.com/app

\section{clinicians $\bullet$ medical students $\bullet$ nurses $\bullet$ healthcare practitioners}

